\title{
Testing for oil saving technological changes in ARDL models of demand for oil in G7 and BRICs
}

\author{
M. Asali \\ Petroleum Studies Department, Research Division, \\ OPEC, Vienna, Austria
}

\begin{abstract}
In recent years, global growth of demand for oil has been mainly due to the increasing demand for energy in major developing nations, namely China, India and Brazil, fueled by their exceptional economic performance. On the other hand, in OECD and particularly in the G7 countries, where more than $70 \%$ of OECD demand for oil is consumed, demand for oil has been stagnant and seems to have plateaued. In fact, per capita, consumption for oil in these countries has been diminishing in recent years. Given the rising share of the major developing economies in the global demand for oil it is important to have a clear idea about their likely future paths of (per capita) demand for oil. A closely related issue is whether energy and oil efficiency in these economies are price induced or could be considered an exogenous process.

In this paper an attempt is made to employ time-series, auto regressive error correction modeling technique to estimate short and long run income and price elasticity's of demand for oil in G7 and the BRICs, (Brazil, Russia, India and China). We have also tested for oil saving technological changes in these economies. This is done by making use of a price decomposition approach and testing for existence of deterministic trend in the estimated demand for oil models. The study yields a set of GDP and price elasticity's of demand for oil in G7 and the BRICs comparable to income and price elasticity's of demand for oil in other studies.
\end{abstract}

Keywords: demand for oil, GDP and price elasticity's, technological changes. 


\section{Introduction}

In this study an attempt is made to estimate (per capita) income and price elasticity's of demand for oil in G7 and BRICs and to see whether the estimated models could shed light on the way the oil saving technological changes impact demand for oil in these economies. The importance of the issue stems from the fact that while G7 countries consume more than $70 \%$ of OECD total oil consumption, incremental demand for oil comes mainly from developing countries particularly China and India with their prominent importance for the global oil markets due to their exceptional economic performance. We have used error correction and ARDL modelling techniques for these purposes. Application of econometric and time series methods have been the traditional approaches to modeling demand for energy and oil. A meaningful application of the time series techniques to modeling demand for oil, however, requires long historical observations on energy consumption, population, income and prices. The starting point of this approach is formulation of suitable energy demand equations, normally derived as decision rules of optimizing households or firms (Pindyck [1], and Pesaran et al. [2]). Huntington [3] in his review of the response surface of several models developed to investigate demand for oil in OECD propose a log-linear, lag-adjustment demand specification consistent with the structure of most models of demand for oil appeared in the literature. This formulation assumes that oil demand responds immediately to changes in income but only gradually to changes in prices. Technical progress, if present, reduces demand at a constant rate in each period and hence operates like income variable.

Here we follow the convenient approach of modeling demand for oil as a function of income and oil prices. In particular we employ linear models and use quarterly time series from 1990Q1 to 2010Q4 to estimate GDP and price elasticity's of demand for oil in G7 and BRICs. To investigate the existence of exogenous oil saving technological changes we test for deterministic linear trends in our time series models. We also make use of price decomposition approach to test for significance of asymmetric response to prices changes in demand for oil in these economies that can be considered as signs of price induced oil saving technological changes in these countries. An asymmetric relationship between oil price and demand for oil may stem from various sources such as irreversibility of improved technological changes, durability of attributes of the petroleum-using capital stock, non-reversal nature of some government policies etc., see Dargay and Gately [4] and Gately and Huntington [5].

The asymmetric relationship between price and consumption is normally modeled by decomposing the price $\mathrm{P}_{\mathrm{t}}$ series into:

$$
\mathrm{P}_{\mathrm{t}}=\mathrm{P}_{0}+\mathrm{P}_{\mathrm{max}, \mathrm{t}}+\mathrm{P}_{\text {rec }, \mathrm{t}}+\mathrm{P}_{\text {cut }, \mathrm{t}}
$$

$\mathrm{P}_{0}$ : The price at the beginning of the sample

$P_{\max , t}$ : The maximum historical price

$P_{\text {rec,t: }}$ : The cumulated price recovery

$\mathrm{P}_{\text {cut, }, \mathrm{t}}$ : The cumulated price cuts. 
The diagnostic tests, namely tests on serial correlation, functional form, normality and heteroskedasticity of the residuals variance, reported along with the estimation results are indicative of robustness and reliability of the estimation results.

The data in this quantitative study is collected from OPEC Data Service Department. As our study is concerned with the quarterly time-series modeling of (per capita) demand for oil in G7 and the BRICs, we have used a quarterly time series of crude oil prices and per capita oil consumption and per capita real GDP. In alternative specifications other variables such as energy and oil intensity are used as well. To calculate the quarterly per capita GDP and demand for oil in the countries of concern we have disaggregated annual population time series to the series with quarterly frequency adopting Denton [6] methodology used by the ECOTRIM 1.01 (Eurostat, 2002) software [7].

The remainder of the paper organized as follows: after a brief review of the modeling methodology in section 2 , the estimation results are presented in section 3 and in section 4 we draw concluding remarks of this paper.

\section{Modelling methodology}

Huntington [3] in his review of the response surface of several models developed to investigate demand for oil in OECD propose a log-linear, lag-adjustment demand specification consistent with the structure of most models. This formulation assumes that oil demand responds immediately to changes in income but only gradually to changes in price. Technical progress, if present, reduces demand at a constant rate in each period and hence operates like income variable. These relationships allow oil demand to be expressed as:

$$
Q_{t}=q_{t}\left(P_{t}\right) e^{g t} Y_{t}^{a} \ldots . . g<0, \ldots a>0
$$

where $\mathrm{Q}$ is actual demand, $\mathrm{P}$ is the oil price, $\mathrm{Y}$ is GDP, $\mathrm{g}$ is the rate of autonomous improvements in oil efficiency, and $\alpha$ is the income elasticity of demand for oil. In this specification, the rate of autonomous improvements is constant each year and demand adjusts completely to income changes within the same year. In contrast, the oil price effect cumulative gradually over time through the variable $\mathrm{q}_{\mathrm{t}}\left(\mathrm{P}_{\mathrm{t}}\right)$.

In each year, after incorporating income and technical progress oil demand adjusts partially to the current price to meet its optimal level.

$$
q_{t} / q_{t-1}=\left(q_{t}^{*} / q_{t-1}\right)^{\lambda} \ldots . .0<\lambda<1
$$

where $\mathrm{q}$ is modified oil demand, $\lambda$ is the fraction of the oil demand adjusted in each period and the asterisk indicates the optimal level of consumption. The optimal level of this variable is itself a function of the oil price alone.

$$
q_{t}^{*}=\alpha P^{\beta}
$$


Substituting for $q_{t}^{*}$ and in (2) and for $q_{t}$ in (1) yields the following expression:

$$
\frac{Q_{t}}{Q_{t-1}}=A P^{\lambda \beta}\left(\frac{Y_{t}}{Y_{t-1}}\right)^{\alpha} Y_{t-1}^{\lambda \alpha} Q_{t-1}^{-\lambda g(t-1)}, \ldots . .
$$

where $\quad A=\alpha^{\lambda} e^{-g}$

In Huntington [3] this equation is estimated by OLS but constraining the coefficients of the non-price terms to their assumed values. In its log form the equation could turn to an $\operatorname{ARDL}(1,1,0)$ in $\mathrm{Q}, \mathrm{P}$ and $\mathrm{Y}$.

$$
\begin{aligned}
& \ln Q_{t}=\alpha^{\prime}+(1-\lambda) \ln Q_{t-1}+\lambda \beta \ln P_{t}+ \\
& \alpha \ln Y_{t}-\alpha(1-\lambda) \ln Y_{t-1}, . w h e r e . . \alpha^{\prime}=-\lambda g(\ln \alpha+t-1)
\end{aligned}
$$

The Huntington Model's specification is typical for most econometric models demand for oil and comparing this specification with the autoregressive distributed lag (ARDL) shows that in fact all the various demand equations can be written in the form of ARDL model of order 1:

$$
\lambda(L) y_{t}=\alpha+b_{1}(L) x_{1 t}+b_{2}(L) x_{2 t}+b_{3}(L) x_{3 t}+u_{t}
$$

where $y_{t}$ denotes the share of energy or oil in total expenditure or logarithm of per-capita energy or oil consumption depending on the particular functional form used in the demand analysis. $X_{t}=1, . ., 3$ are the logarithms of oil and non-oil prices and real output.

$$
\begin{aligned}
& \lambda(L)=1-\lambda L \\
& b_{i}(L)=b_{0}+b_{1} L
\end{aligned}
$$

$\mathrm{L}$ is as usual one-period lag operator $\left(\mathrm{Lx}_{1, \mathrm{t}}=\mathrm{w}_{1, \mathrm{t}-1}\right)$, and $\mathrm{u}_{\mathrm{t}}$ serially uncorrelated error term. This model is general enough four our purpose and yields the various dynamic formulations of energy demand equations discussed earlier.

In the context of the ARDL model (6), the parameters of interest are the long term coefficients

$$
\begin{gathered}
\theta_{j}=\left(b_{j 0}+b_{j 1}\right) /(1-\lambda), \ldots . . j=1,2,3 \\
\psi=a /(1-\lambda)
\end{gathered}
$$

The speed of adjustment is defined by $\psi$. In terms of the parameters, (6) can be written in the form of an error correction (EC) model:

$$
\Delta y_{t}=-\varphi E C_{t-1}+\sum_{j=1}^{3} b_{j 0} \Delta x_{j t}, \ldots \ldots \ldots . . t=1,2, \ldots ., T
$$


where the error correction term is the deviation from the long term relationship.

$$
E C_{t}=y_{t}-\sum_{j=1}^{3} \theta_{j} x_{j t}-\psi
$$

The remaining parameters, $b_{j 0}, \mathrm{j}=1,2,3$ represent the impact effect of the price and income changes on energy consumption. As mentioned earlier a number of dynamic models are nested within the above general ARDL $(1,1,1,1)$ specification. For example, the simple partial adjustment is obtained by setting $b_{j 1}=0, \mathrm{j}=1,2,3$. The simple error correction model is obtained by restricting the impact effects to be zero, namely $b_{j 0}=0, \mathrm{j}=1,2,3$.

From this discussion it is therefore visible that all the various demand equations that we estimate can be written in the form presented above. The base line country specific (ARDL) model, general form of which was given by equation (6) can be represented for the first order ARDL model in a time series framework as follows:

$$
\begin{aligned}
& y_{t}=a_{i}+\lambda_{i} y_{, t-1}+b^{\prime}(L) x_{t i}+u_{t}, \ldots . t=1,2, \ldots, T \\
& \text { where. } b=b_{0}+b_{L}, \ldots
\end{aligned}
$$

As before, $\mathrm{y}_{\mathrm{t}}$ is logarithm of energy consumption in country $\mathrm{i}$ at time $\mathrm{t}, \mathrm{x}_{\mathrm{t}}$ is a $\mathrm{k} x 1$ vector of explanatory variables for country $\mathrm{i}$. This model provides a useful initial framework for investigating the consequence of pooling and can be generalized to higher order ARDL and its error correction form can be written either in terms of lagged error correction form.

$$
\Delta y_{t}=a_{i}-\varphi\left(y_{, t-1}-\theta_{i}^{\prime} x_{, t-1}\right)+b_{0}^{\prime} \Delta x_{t}+u_{t}
$$

or as a partial adjustment type error correction plus change, Pesaran et al. [2]

$$
\Delta y_{t}=a-\varphi\left(y_{t-1}-\theta^{\prime} x_{t}\right)-b_{1}^{\prime} \Delta x_{t}+u_{t}
$$

where the adjustment coefficient, $\varphi=1-\lambda$, and the long run response of $y_{t}$ to a unit change in $x_{t}$ is given by the $k x 1$ vector $\theta=\left(b_{0}+b_{1}\right) /(1-\lambda)$. The dynamic of the adjustment towards equilibrium in this simple setting are governed by $\varphi$ and $b^{\prime}{ }_{0}$ or $b^{\prime}{ }_{1}$. The disturbance terms will be assumed to be independently normally distributed across time with expected value zero and variances $\sigma^{2}$. Assumptions that there exists a long run relationship between $y_{t}$ and $x_{t}$ can be tested using cointegration technique if it is known that the time series are integrated of order one I (1). In the next section we investigate these points. 


\section{Price homogeneity, unit roots and co-integration tests}

Typically there are four steps in testing for co-integrating relationship between the time series of a VAR model:

i) Implementing unit root tests to see if the series are I (1),

ii) Investigating the nature of the intercept/trend in the underlying VAR based on in-differenced data to see if the intercept and the deterministic time trend or both should be included,

iii) Selecting the order of VAR and

iv) Estimating the co-integrating VAR and carrying out the tests.

Overall, this standard procedure is followed here, however, we have added a price homogeneity test to this four step procedure in order to give a statistical justification for substituting the real domestic oil price $(\mathrm{P} / \mathrm{Cpi})$ for the two prices variables, namely imported oil prices in domestic currency series divided and domestic consumer price index in the EC model specification.

The test results are presented in the table 1. It is clear from the table that the joint hypothesis of long run and short run restrictions are generally accepted in all countries of the sample.

Table 1: $\quad$ F-statistics for testing restrictions "Long run and short run price homogeneity" on the basic EC equation.

\begin{tabular}{|c|c|c|c|c|c|c|}
\hline \multirow{2}{*}{ Country } & \multicolumn{3}{|c|}{$\begin{array}{c}\text { Long-run } \\
\text { price homogeneity (HI) }\end{array}$} & \multicolumn{3}{|c|}{$\begin{array}{l}\text { Long-run and short-run } \\
\text { price homogeneity }(\mathrm{H})\end{array}$} \\
\hline & F-statistic & $\begin{array}{l}\text { Degree of } \\
\text { freedom }\end{array}$ & Prob. & F-statistic & $\begin{array}{l}\text { Degree of } \\
\text { freedom }\end{array}$ & Prob. \\
\hline Brazil & 0.022 & $F(1,24)$ & 0.88 & 1.27 & $F(2,24)$ & 0.29 \\
\hline Canada & 0.046 & $F(1,73)$ & 0.82 & 2.32 & $F(2,73)$ & 0.10 \\
\hline China & 0.068 & $F(1,55)$ & 0.79 & 0.92 & $F(2,55)$ & 0.40 \\
\hline France & 2.34 & $F(1,63)$ & 0.13 & 1.92 & $F(2,63)$ & 0.15 \\
\hline Germany & 1.22 & $F(1,73)$ & 0.27 & 1.40 & $F(2,73)$ & 0.25 \\
\hline India & 1.73 & $F(1,60)$ & 0.19 & 1.21 & $F(2,60)$ & 0.31 \\
\hline Italy & 2.43 & $F(1,73)$ & 0.12 & 2.63 & $F(2,63)$ & 0.08 \\
\hline Japan & $5.11^{*}$ & $F(1,73)$ & 0.03 & 2.77 & $F(2,73)$ & 0.07 \\
\hline Russia & 0.23 & $F(1,25)$ & 0.63 & 0.16 & $F(2,25)$ & 0.85 \\
\hline UK & 1.91 & $F(1,73)$ & 0.17 & 0.95 & $F(2,73)$ & 0.39 \\
\hline USA & $5.60 *$ & $F(1,73)$ & 0.02 & 2.80 & $F(2,73)$ & 0.07 \\
\hline
\end{tabular}

This opens the way for our investigation of the nature of intercept/trend in underlying VAR model and now we can return to the four step co-integration testing procedure starting by estimating an unrestricted VAR with the three variables, namely, (per capita) demand for oil (LD), real (per capita) GDP (LY) and constant oil price (LP) all in logarithms to determine whether the intercept and trend should be included in the equations. For each individual country, we 
therefore, estimate an unrestricted VAR with six lags and examine whether two deterministic variables, $\mathrm{C}$ and $\mathrm{T}$, should be included. The results are summarized in the following sections.

The unit root test results (not reported here for space limitations) show that all the variables concerned, in our demand for oil modelling, are integrated of the order one I (1) that opens the way for our ECM analysis. This analysis will need testing for co-integration between the variables. But prior to investigating the nature of intercept/trend in the underlying VAR models and selecting the order of VAR models to arrive at co-integration tests, here as was mentioned, we have tested the hypothesis of the long run and short run price homogeneity in individual countries.

For each individual country we therefore estimate an unrestricted VAR with six lags and examine whether two deterministic variables, $\mathrm{C}$ and $\mathrm{T}$, should be included. The results (not reported here) indicate that for all countries of the sample group the null hypothesis of zero intercept or zero trends or zero intercept and trend together for all three time series is rejected except in the case of the UK that one cannot reject the null of zero intercept or zero trend at $5 \%$ level. However, even in this case the null hypothesis of zero restriction on both intercept and trend is rejected at 5\% level.

Having tested for including $\mathrm{C}$ and $\mathrm{T}$ in the unrestricted models we next could use information criteria to select the appropriate order of the VARs. Different information criterions have selected different lag lengths for the same country and for different countries of the sample group. The optimal lag lengths differ from 2 lags selected by SC for Italy and China to up to 6 lags by different criterions for Brazil and Russia. Generally speaking it appear that the criteria have selected less lags for VAR models of G7 countries; around three lags; than for the BRICs on average. Brazil and Russia are given 6 lags by all the criteria. Since it is believed that AIC tends to overestimate the lag length whereas SBC and HQC are consistent estimators, here we have given more weight to SBC in selecting lag length of the VAR models particularly when both SBC and HQC select the same $\mathrm{m}$. In fact with large sample and assuming true model is amongst those considered, the SBC and HQC will choose the correct model. This is supported by simulation evidence for example by Basci and Zaman [8]. They show that for large samples the SBC and HQC are unambiguously the best criteria to use. Also we know that Eviews [9] uses SBC when choosing $\mathrm{m}$ in lag length selection of VARs.

In view of the discussion above we will assume the optimal lags for the sample countries models as follows: Brazil 6, Canada 3, China 6, France 3, Germany 3, India 3, Italy 2 and 3, Japan 3, Russia 6, UK 3 and USA 3. Assuming these selected lag lengths the null hypothesis of inclusion of intercept or trend, and intercept and trend together in demand for oil equations of individual economies are tested calculating log-Likelihood ratios, (the results are not given here to save space).

Overall, the likelihood ratio tests with the selected lag length for each country of the sample group do not change the general picture, where all the VAR models were of order 6. Only in case of India, where the selected lag length is 3, 
estimating the corresponding VAR model with no intercept results in a Log Likelihood ratio of 3.4 which is less than the critical value of 7.8 , meaning that in this case the null hypothesis of zero intercept cannot be rejected at $5 \%$ level. For the remaining cases zero restriction on intercept and trend or both intercept and trend together is rejected. With these results, given the non-stationarity of the time series of concern, we now turn to co-integration tests to investigate the existence of long run relationship between the time series for each individual economy of our sample group. Given the co-integration tests results; we will then use a combination of error correction and its equivalent ARDL models of per capita demand for oil in individual economies to arrive to the best estimations of price and income elasticity's of demand for oil in these countries on the basis of diagnostic tests.

Application of the Johansen co-integrations tests reveal that, as expected, the three time series of concerned, namely: per capita demand for oil, per capita real GDP and real price of (imported) oil are co-integrated in all economies of the sample group, albeit with different lag intervals and deterministic trend assumptions in different economies of the sample group. Having established the co-integrating relation between the variables of concern we next turn to estimate the ARDL version of the error correction models for each individual economy before attending to the pooled cross country estimations of the parameters of the models.

\section{Individual country results estimating ARDL $(1,0,0)$ models}

The following table gives the individual country estimations results. The diagnostic tests results (not given here to save space) imply that all the equations pass the diagnostic tests, namely Lagrange multiplier test for serial correlation, functional form misspecification, non-normal errors and heteroskedasticity tests at the 5 per cent level, except for heteroskedasticity test for the UK equation that is at $1 \%$ level. As can be seen from table 2, all the estimated income and price elasticity's are of the right sign and in the main comparable to other studies of demand for oil. The average for GDP elasticity of demand for oil for the eleven countries of our sample is estimated to be 0.41 in the short run and 0.78 in the long run. For the price elasticity of demand for oil the average value of eleven country sample in the short and long run are -0.05 and -0.15 respectively.

In this table $\hat{\varphi}$ is the coefficient of adjustment or error correction term, $\bar{R}^{2}$ is the adjusted squared multiple correlation coefficient model, and gives the proportion of the changes in demand for per capita oil explained by the model. LL is the maximized value of the likelihood of the estimated equation. All the equations fit quite well, the lowest fit being the estimated model for Germany with $\bar{R}^{2}$ equal to 0.83 .

The estimated equation for France yields the largest short and long run (per capita) GDP elasticity of demand for oil; 0.89 and 1.35 respectively, followed by Italian equation with the estimated short and long run elasticity's of 0.86 and 1.32 respectively. Smallest income elasticity for the short run and long run are 
Table 2: $\quad$ Income and price elasticity's based on ARDL $(1,0,0)$ specifications.

\begin{tabular}{|c|c|c|c|c|c|c|c|}
\hline \multirow[b]{2}{*}{ Country } & & \multicolumn{2}{|c|}{ Elasticity } & \multirow[b]{2}{*}{ t-ratio } & \multirow{2}{*}{$\begin{array}{c}\text { Coef. } \\
\text { of adj. } \\
\hat{\varphi}\end{array}$} & \multirow[b]{2}{*}{$\begin{array}{l}\text { Adj. } \\
\mathrm{R}^{2}\end{array}$} & \multirow[b]{2}{*}{ LL } \\
\hline & & $\begin{array}{l}\text { Short- } \\
\text { run }\end{array}$ & $\begin{array}{l}\text { Long- } \\
\text { run }\end{array}$ & & & & \\
\hline \multirow[t]{2}{*}{ Brazil } & Income & 0.32 & 0.82 & 5.18 & \multirow[t]{2}{*}{0.38} & \multirow[t]{2}{*}{0.97} & \multirow[t]{2}{*}{113.6} \\
\hline & Price & -0.02 & -0.06 & -2.23 & & & \\
\hline \multirow[t]{3}{*}{ Canada } & Income & 0.15 & 0.35 & 5.24 & \multirow[t]{3}{*}{0.42} & \multirow[t]{3}{*}{0.91} & \multirow[t]{3}{*}{212.5} \\
\hline & Price_max & -0.06 & -0.13 & -4.33 & & & \\
\hline & Price rec & 0.01 & 0.03 & 3.93 & & & \\
\hline \multirow[t]{4}{*}{ China } & Income & 0.57 & 0.89 & 4.19 & \multirow{4}{*}{0.64} & \multirow{4}{*}{0.98} & \multirow{4}{*}{125.1} \\
\hline & Price_max & -0.08 & -0.13 & -1.60 & & & \\
\hline & Price rec & 0.0 .7 & 0.10 & 1.97 & & & \\
\hline & Price_cut & 0.09 & 0.14 & 3.24 & & & \\
\hline \multirow[t]{2}{*}{ France* } & Income & 0.89 & 1.35 & 4.71 & \multirow[t]{2}{*}{0.63} & \multirow[t]{2}{*}{0.84} & \multirow[t]{2}{*}{187.3} \\
\hline & Price & -0.03 & -0.05 & -2.50 & & & \\
\hline \multirow{3}{*}{ Germany } & Income & 0.25 & 0.46 & 4.49 & \multirow[t]{3}{*}{0.55} & \multirow[t]{3}{*}{0.83} & \multirow[t]{3}{*}{176.6} \\
\hline & Price max & -0.04 & -0.09 & -4.43 & & & \\
\hline & Price_rec & -0.03 & -0.06 & -8.56 & & & \\
\hline \multirow[t]{3}{*}{ India } & Income & 0.30 & 0.80 & 3.99 & \multirow[t]{3}{*}{0.40} & \multirow[t]{3}{*}{0.99} & 197.8 \\
\hline & Price_max & -0.05 & -0.12 & -2.02 & & & \\
\hline & Price_rec & 0.05 & 0.11 & 2.95 & & & \\
\hline Italy* & Income & 0.86 & 1.32 & 6.48 & 0.66 & 0.95 & 207.1 \\
\hline & Price & -0.06 & -0.09 & -4.91 & & & \\
\hline Japan & Income & 0.45 & 0.85 & 3.04 & 0.525 & 0.92 & 199.9 \\
\hline & Price max & -0.09 & -0.18 & -5.66 & & & \\
\hline & Price_rec & -0.02 & -0.05 & -3.70 & & & \\
\hline Russia & Income & 0.11 & 0.63 & 4.48 & 0.184 & 0.96 & 182.2 \\
\hline & Price rec & -0.03 & -0.15 & 2.46 & & & \\
\hline UK & Income & 0.16 & 0.38 & 2.73 & 0.42 & 0.91 & 228.9 \\
\hline & Price_rec & -0.01 & -0.023 & -1.70 & & & \\
\hline & Price_cut & 0.021 & 0.05 & 2.63 & & & \\
\hline USA* $^{*}$ & Income & 0.42 & 0.70 & 3.15 & 0.575 & 0.92 & 255.9 \\
\hline & Price $\max$ & -0.10 & -0.18 & -4.25 & & & \\
\hline & Price_cut & 0.01 & 0.02 & 1.72 & & & \\
\hline Average & Income_11 & $\begin{array}{c}0.41 \\
-0.05\end{array}$ & $\begin{array}{c}0.78 \\
-0.15\end{array}$ & & 0.49 & & \\
\hline
\end{tabular}

Russian and Canadian with the estimated values of 0.11 and 0.35 respectively. This is worth noting that the largest GDP elasticity's are estimated for those equations with a deterministic trend in the final specification. It seems that in these equations the deterministic trend, that captures the oil saving exogenous technological change effect, allows the GDP elasticity's of demand for oil to be higher. By final specification we mean the specification that yields the best fit considering criteria such as R squared, log likelihood statistics (Akaike [10]), Information Criteria and Schwarz [11] Criterion and at the same time passes all 
the diagnostic tests of serial correlation, functional form test, normality test and heteroskedasticity test.

\section{Concluding remarks}

The long-run income and price elasticity's for all the sample countries estimated in this study seem to be in a plausible range. One interesting aspect of our modelling approach is that it allows to test whether energy savings in the sample countries are exogenous or induced by oil prices changes. Observe that final specifications of demand for oil for three countries, namely France, Italy and USA contain a deterministic trend. This could be interpreted as presence of a significant impact from exogenous technological changes on demand for oil in these countries. To capture the price induced energy saving technological changes we have made use of the price decomposition, as discussed in Dargay and Gately [4] and Gately and Huntington [5]. In empirical studies, decomposition of prices in models of demand for oil is in effect testing for asymmetric relationship between oil prices and its consumption.

In view of this discussion the estimation results lend themselves to the interpretation that in the cases of France, Italy and the USA, the deterministic trend, that captures the oil saving exogenous technological change effect, allows the GDP elasticity's of demand for oil to be higher. In fact excluding the deterministic trend effect from theses equations would have resulted the short run GDP elasticity of demand for oil equal to 0.46 for France, 0.49 for Italy and 0.37 for the USA with corresponding long rum income elasticity's of $0.76,0.74$ and 0.64 respectively. These values of income elasticity of demand for oil are closer to the average value of this parameter for the G7 and the sample group of eleven countries.

If decomposition of oil prices in equations of demand for oil can be considered as a substitution for stochastic trend of oil saving technological changes (Agnolucci [12]) then one can say that in all countries of the sample group other than Brazil, France and Italy there have been statistically significant evidence of price induced oil saving technological change in these economies. Of the remaining three countries, the parameters to the deterministic trend, that captures the exogenous oil saving technological changes, are statistically significant for the French and Italian equations. This is only Brazilian equation that in its final specification does not incorporate neither deterministic nor stochastic trends. On the other hand this is only the US equation that comprises both deterministic and stochastic trends indicating the existence of both exogenous and price induced oil saving technological changes in this economy.

\section{References}

[1] Pindyck, R. (1979) “The structure of world energy demand" The IMT Press.

[2] Pesaran, M. H., R. P. Smith, T. Akiyama (1998) "Energy Demand in Asian Developing Economies", Oxford University Press and Oxford Institute for Energy Studies. 
[3] Huntington, H. (1993) "Estimated response surface for nine world oil models" Energy Economics, January.

[4] Dargay, J. and D. Gately (1995a) "The imperfect price reversibility of non-transport oil demand in the OECD" Energy Economics 17(1): 59-71.

[5] Gately, D. and H.G. Huntington (2002) "The asymmetric effect of changes in price and income on energy and oil demand" Energy Journal, 23 (1): 19-55.

[6] Denton, F. T. (1971), “Adjustment of monthly or quarterly series to annual totals: An approach based on quadratic minimization, Journal of the American Statistics Association 66 (333).

[7] Barcellan, R., and Buono, D. (2002) "Temporal Disaggregation Techniques: Ecotrim Interface", User Manual, Eurostat, The Statistical Office of European Commission.

[8] Basci, S and A. Zaman (1998) "Effects of Skewness and Kurtosis on Model selection Criteria" Economic Letters, 59, PP 17-22.

[9] Quantitative Micro software (2007) "Eviews 6 User Manual", CA, USA.

[10] Akaike, H. (1973), "Information Theory and the Extension of the Maximum Likelihood Principle" in Proceedings of the Second International Symposium of Information Theory, eds. B. N. Petrov and F. Csaki, Budapest, PP. 267-281.

[11] Shwarz, G. (2978), "Estimating the Dimension of a Model", Annals of Statistics, 6, PP. 461-4.

[12] Agnolucci, P. (2010) "Stochastic Trends and Technical Changes: The Case of Energy Consumption in the British Industrial and Domestic sectors" The Energy Journal, Vol.31, No. 4.0. 